\title{
Corrigendum
}

\section{Internationalisation of Indian knowledge- intensive service firms: Learning as an antecedent to entrepreneurial orientation}

\author{
Nishant Kumar
}

Asian Business \& Management (2015) 14, 249. doi:10.1057/abm.2015.7

Correction to: Asian Business \& Management (2013) 12(5), 503-523. doi:10.1057/abm.2013.20

The editor and publisher wish to point out that several references are absent from the bibliography, or insufficiently cited in the full text of this article. This is an unfortunate error by the author, relating almost exclusively to the 'Theoretical Background' and 'Research Method' sections. After close investigation, we conclude there is no evidence that this inadequate use of references has affected the original research of this article, which is why it shall remain in the academic record. We would like to extend our apologies for the absence of the following, which should have been included in the references:

Kumar, N. (2013) The importance of human capital in the early internationalisation of Indian knowledge-intensive service firms. International Journal of Technological Learning, Innovation and Development 6(1/2) 21-41.

Kumar, N. (2012) Exploring the effects of human capital loss on relationships with clients in knowledge-intensive service firms and the moderating effect of knowledge management. International Journal of Globalisation and Small Business. 4(3/4) 342-359.

Kumar, N. (2012) International Entrepreneurship: Case of Happiest Minds. South Asian Journal of Business and Management Cases 1(1) 17-30.

Sepulvida, F. (2010) The Entrepreneurial Orientation of Rapidly Internationalizing Service Firms and its Link to International Operations. Competitive Paper submitted to: The Eighteenth Annual High Technology Small Firms Conference Enschede, Netherlands May 27-28 2010. 